\title{
The Environmental Kuznets Curve and Flow versus Stock Pollution: The Neglect of Future Damages
}

\author{
CHRISTOPH MARTIN LIEB ${ }^{1,2}$ \\ ${ }^{1}$ Interdisciplinary Institute for Environmental Economics, University of Heidelberg, Germany; \\ ${ }^{2}$ Ecoplan, Bern, Switzerland (e-mail: lieb@ecoplan.ch)
}

Accepted 28 April 2004

\begin{abstract}
In this paper we offer a possible explanation for the empirical finding that the pollution-income relationship (PIR) for flow pollutants is an environmental Kuznets curve (EKC), i.e. inverted-U shaped, but that the PIR for stock pollutants is monotonically rising. We analyse an overlapping generations model with two pollutants: The flow pollutant causes immediate damages, but the stock pollutant harms the environment only in the future. Hence, a succession of myopic governments lets stock pollution grow with income. In contrast, the flow pollutant follows an EKC whose downturn might be caused by the neglect of future damages and by ever rising stock pollution: Without the stock pollutant the PIR for the flow pollutant can increase monotonically. We also show that the turning point of the EKC for the flow pollutant lies at lower levels of income and of flow pollution if stock pollution is high and harmful. This casts doubts on most empirical EKC studies because they assume that the turning point occurs at the same income level in all countries. However, it is consistent with recent empirical findings that the income level at the turning point of the $\mathrm{EKC}$ varies across countries.
\end{abstract}

Key words: abatement, economic growth, environmental Kuznets curve, flow and stock pollution, myopia

JEL classification: D62, O41, Q20

\section{Introduction}

In the last decade a vast amount of empirical studies have analysed the pollution-income relationship (PIR). These studies have tried to find out whether or not pollution is rising with income at low income levels, but falling at higher income levels. Such an inverted-U shaped pattern of the PIR is called an environmental Kuznets curve (EKC). Although empirical studies could only verify the EKC for a few flow pollutants, the EKC was frequently interpreted as a reason for optimism or even as an indication that economic growth will eventually solve all environmental problems. By offering a new 
possible explanation of the EKC we show that these views might be overly optimistic: In our model the downturn of the EKC for a flow pollutant might be due to the neglect of future damages and due to ever rising stock pollution.

One of the main purposes of this paper is to find a possible explanation for the empirical evidence that the PIR is an EKC for flow pollutants, but that the PIR is monotonically rising for stock pollutants. Although the estimated turning points of the EKCs differ considerably between studies, almost all studies agree that there is an EKC for sulphur dioxide $\left(\mathrm{SO}_{2}\right)$, suspended particulate matter $(\mathrm{SPM})$, oxides of nitrogen $\left(\mathrm{NO}_{x}\right)$, carbon monoxide $(\mathrm{CO})$, and for some (but not all) sorts of river pollution (RP) as shown in Table I. Although all these pollutants are stock pollutants, they all have short lifetimes and can therefore be considered as flow pollutants from a long-run point of view: In the atmosphere the lifetime of $\mathrm{SO}_{2}$ is $1-4$ days, that of $\mathrm{NO}_{x}$ is $2-5$ days, ${ }^{1}$ and that of CO is $1-3$ months (Liu and Lipták 2000, p. 32 and IPCC 1996, p. 92, for a definition of lifetime see IPCC 1996, p. 76). SPM is washed out by rain- and snowfalls (Liu and Lipták 2000, p. 34) and thus has only a short lifetime. Since rivers are flowing, the concentrations of river pollutants would quickly decline if emissions stopped. So river pollutants are short-lived. Thus they can also be considered as flow pollutants. However, for municipal waste the estimated PIR is monotonically rising (see Table I). Municipal waste is a stock pollutant since it is deposited and accumulates in waste disposal sites. ${ }^{2}$ For the stock pollutant carbon dioxide $\left(\mathrm{CO}_{2}\right)$ with a lifetime of about 125 years (Frey et al. 1991, p. 165) the evidence is mixed. However, as Table I shows the vast majority of researchers finds a monotonically rising PIR or an EKC with a turning point which lies (far) outside the income sample range. ${ }^{3}$

To explain this evidence we develop an overlapping generations model based on the model of John and Pecchenino (1994). While there is only one pollutant in the model of John and Pecchenino (1994), we extend the model to two pollutants. To my knowledge this is the first model of the EKC with two pollutants.

In the model the economy is equipped with a production technology which causes emissions of a flow and of a stock pollutant. On the one hand, the flow pollutant has an immediate and only an immediate effect on the environment. On the other hand, the stock pollutant harms the environment only in the future since stock pollutants frequently need time to accumulate before the damage occurs. Furthermore, there are two abatement technologies - one for each pollutant. Myopic governments never abate the stock pollutant because the positive effects are only felt in the future which is of no concern for myopic governments. Therefore we show that on the path followed by a succession of myopic governments the PIR for the stock pollutant is monotonically rising while the PIR for the flow pollutant is an EKC. This is consistent with the empirical evidence. The EKC stems from the fact that myopic governments 
Table I. Empirical results for the PIR of several pollutants

\begin{tabular}{|c|c|c|c|c|c|c|c|}
\hline & \multicolumn{5}{|c|}{ Flow pollutants } & \multicolumn{2}{|c|}{$\begin{array}{l}\text { Stock } \\
\text { pollutants }\end{array}$} \\
\hline & $\mathrm{SO}_{2}$ & SPM & $\mathrm{NO}_{x}$ & $\mathrm{CO}$ & $\mathrm{RP}$ & Waste & $\mathrm{CO}_{2}$ \\
\hline Grossman and Krueger (1993) & $\frown$ & $\sim$ & & & & & \\
\hline Selden and Song (1994) & $\frown$ & $\frown$ & $\frown$ & is & & & \\
\hline Shafik (1994) & $\frown$ & $\frown$ & & & $\sim$ & $\nearrow$ & $\nearrow$ \\
\hline Grossman (1995) & $\sim$ & $\frown$ & $\frown$ & $\frown$ & & & \\
\hline Grossman and Krueger (1995) & $\sim$ & $\frown$ & & & $\frown$ & & \\
\hline Holtz-Eakin and Selden (1995) & & & & & & & $\nearrow$ \\
\hline Panayotou (1995) & $\frown$ & $\frown$ & $\frown$ & & & & \\
\hline Carson et al. (1997) & $\frown$ & $\frown$ & $\frown$ & $\frown$ & & & $\frown$ \\
\hline Cole et al. (1997) & $\frown$ & $\frown$ & $\frown$ & $\frown$ & $\frown$ & $\nearrow$ & $\nearrow$ \\
\hline $\operatorname{Lim}(1997)$ & $\frown$ & $\frown$ & $\frown$ & & $\frown$ & & $\nearrow$ \\
\hline Moomaw and Unruh (1997) & & & & & & & $\sim$ \\
\hline Panayotou (1997) & $\sim$ & & & & & & \\
\hline Roberts and Grimes (1997, p. 192) & & & & & & & $\nearrow$ \\
\hline Kaufmann et al. (1998) & $\sim$ & & & & & & \\
\hline Schmalensee et al. (1998) & & & & & & & $\frown$ \\
\hline Scruggs (1998) & $\frown$ & $\frown$ & & & & & \\
\hline Torras and Boyce (1998) & $\sim$ & $\frown$ & & & $\frown$ & & \\
\hline Wu (1998) & & $\frown$ & & & & & \\
\hline Agras and Chapman (1999) & & & & & & & $\neg 1 \nearrow$ \\
\hline Barrett and Graddy (2000) & $\sim$ & $\frown$ & & & $\frown$ & & \\
\hline Cavlovic et al.(2000) & $\frown$ & $\frown$ & $\frown$ & $\frown$ & $\frown$ & & $\nearrow$ \\
\hline Cole $(2000$, p. 112) & $\frown$ & & $\frown$ & & & & \\
\hline Dinda et al.(2000) & $\frown$ & $\sim$ & & & & & \\
\hline Hettige et al. (2000) & & & & $\frown$ & & & \\
\hline List and Gerking (2000) & $\frown$ & & $\frown$ & & & & \\
\hline Perrings and Ansuategi (2000) & $\frown$ & & & & & & $\nearrow$ \\
\hline Halkos and Tsionas (2001) & & & & & & & $\nearrow$ \\
\hline Heil and Selden (2001) & & & & & & & $\nearrow$ \\
\hline Minliang et al. (2001) & & & & & & $\nearrow$ & \\
\hline Roca et al. (2001) & $\sim$ & & is & & & & $\nearrow$ \\
\hline Stern and Common (2001) & $\neg /$ & & & & & & $\nearrow$ \\
\hline Hill and Magnani (2002) & $\frown$ & & $\frown$ & & & & $\neg 1 \nearrow$ \\
\hline Friedl and Gletzner (2003) & & & & & & & $\sim$ \\
\hline Millimet et al. (2003) & $\frown$ & & $\frown$ & & & & \\
\hline
\end{tabular}

Note: $\mathrm{SPM}$ - suspended particulate matter; $\mathrm{RP}$ - river pollution; $\frown-\mathrm{EKC}$; $\nearrow$ - the PIR is monotonically rising or the EKC has an out-of-sample turning point. $\sim-$ the PIR is N-shaped (first rising, then falling, and finally rising again) with both turning points inside the sample range. is - insignificant. $\frown / \nearrow$ results of two different estimations. 
abate flow pollution in order to keep the aggregate damage of both pollutants at a reasonably low level. Because stock pollution increases, abatement of the flow pollutant rises so fast that flow pollution declines.

If there is no stock pollutant, however, it is possible that flow pollution rises monotonically with income. Thus the growth of the stock pollutant can actually cause the EKC for the flow pollutant. Without the stock pollution we are back at a one-pollutant model. In this case the model for the flow pollutant is very similar to the model of Lieb (2002) and Stokey (1998): We find an EKC for the flow pollutant when the tendency to satiation in consumption is sufficiently strong. Otherwise, the PIR is monotonically rising.

A further aim of the paper is to give a possible explanation for some additional empirical findings: Recent studies show that the turning point of the EKC occurs at different income levels in different countries (Koop and Tole 1999; List and Gallet 1999; de Bruyn 2000, pp. 105-106). This is exactly what we find in the model: The location of the turning point of the EKC for the flow pollutant depends on the level and harmfulness of stock pollution, the ("greenness" of the) utility function, the level of flow pollution and the production function of the polluting industry. All these parameters tend to be different in different countries. Thus the income level at the turning point of the EKC for the flow pollutant may differ across countries because stock pollution varies across countries and because stock pollution drives abatement of the flow pollutant.

We only analyse the myopic solution in this paper. There are good reasons to focus on the myopic solution: It is impossible to internalize all environmental damages, first, because of coordination problems and transaction costs (Smulders 2000, pp. 641-642) which make it simply infeasible to closely monitor all (potential) pollutants ${ }^{4}$ and, second, because some damages are difficult to measure, in particular soil erosion (van Kooten and Bulte 2000, p. 387), desertification, pollution and depletion of groundwater aquifers, biodiversity loss (Cole 1999, p. 95), acidification (Neumayer 1998, p. 168), extinction of animal and plant species, climate change, and the risk of nuclear power stations. So there are always unregulated pollutants. ${ }^{5}$ These pollutants tend to be stock pollutants since the incentives to monitor them are smaller than for flow pollutants (Arrow et al. 1995, p. 92). Hence, the myopic solution of our model might be closer to reality than the farsighted one. In fact, the myopic solution is consistent with the empirical evidence.

Abatement of flow, but not of stock pollutants might also be the outcome of a lobbying process: To pacify the "green" lobby the government cannot be inactive. To lose as little votes as possible the government abates flow pollutants because the improvements can immediately be discerned while the abatement of stock pollutants would not be perceived by the uninformed electorate. 
In this paper we concentrate attention on flow and stock pollutants. However, similar results as derived in this paper might also be found in other situations: local pollutants might be abated while emissions of transboundary or global pollutants increase. Or there might be a rise in emissions of a (hitherto not emitted) chemical substance whose effects on the environment are not yet known (de Bruyn 2000, p. 87). Energy gained from fossil fuels might also be replaced by nuclear power - an energy source with its own problems (Scruggs 1998, pp. 269-271). Finally, pollution might only be relocated: The polluting firms in high-income countries might just migrate to lower income countries (Arrow et al. 1995; Saint-Paul 1995).

This paper is organized as follows. Section 2 presents the assumptions of the model. In Section 3 we solve the model and derive the phase diagram with which we examine the optimal path followed by of a succession of myopic governments in Section 4. Two important consequences of this path are discussed in Section 5. Section 6 concludes.

\section{The Model}

To analyse the interaction of stock and flow pollutants an overlapping generations model is used. The model is an extension to two pollutants of the model of John and Pecchenino (1994). In every period a new generation is born which lives for two periods. The population size of each generation is assumed to be constant at $L$. In each period there are people of two different generations: The young and the old. While only the young are working and get a wage in return, only the old derive utility from consumption $c$ and suffer from pollution $P$ (small letters indicate per capita values). ${ }^{6}$ Utility $u$ of the representative consumer is given by $u(c, P)$ for each generation where $u_{c}>0$ and $u_{P}<0$. The marginal rate of substitution is defined by $\mathrm{MRS}=$ $-u_{c} / u_{P}>0$. We assume that consumption and environmental quality (or $-P$ ) are both normal goods. This can be written as (see Lieb 2002, pp. 432$433)^{7}$

$$
\begin{aligned}
\mathrm{MRS}_{c} & =\frac{\partial \mathrm{MRS}}{\partial c}=\frac{-u_{c c} u_{P}+u_{P c} u_{c}}{u_{P}^{2}}<0 \\
\mathrm{MRS}_{P} & =\frac{\partial \mathrm{MRS}}{\partial P}=\frac{-u_{c P} u_{P}+u_{P P} u_{c}}{u_{P}^{2}}<0 .
\end{aligned}
$$

Competitive firms produce output $Y$ using capital $K$ and labour $L$ in a Cobb-Douglas production function with constant returns to scale. Thus in period $t$ we have $Y_{t}=F\left(K_{t}, L_{t}\right)=\beta K_{t}^{\alpha} L_{t}^{1-\alpha}$, where $0<\alpha<1$. Dividing the production function by $L$ we obtain $y_{t}=f\left(k_{t}\right)=\beta k_{t}^{\alpha}$, where $y=Y / L$ and $k=K / L$ are per capita values. ${ }^{8}$ Firms maximize their profits (where the consumption good is the numeraire good) 


$$
\max _{K, L} \beta K_{t}^{\alpha} L_{t}^{1-\alpha}-w_{t} L_{t}-r_{t} K_{t}-\delta K_{t}
$$

taking as given the wage $w$, the interest rate $r$, and the depreciation rate of capital $\delta$. Solving this problem we find

$$
\begin{aligned}
& r_{t}=\alpha \beta K_{t}^{\alpha-1} L_{t}^{1-\alpha}-\delta=\alpha \beta k_{t}^{\alpha-1}-\delta, \\
& w_{t}=(1-\alpha) \beta K_{t}^{\alpha} L_{t}^{-\alpha}=(1-\alpha) \beta k_{t}^{\alpha} .
\end{aligned}
$$

As labour is supplied inelastically by the young, the wage adjusts to ensure equilibrium in the labour market. The capital market is discussed below.

Since it is argued that pollution as perceived by the general public is an aggregate measure (Wu 1998), we assume that pollution $P$ is the sum of the two pollutants $P^{1}$ and $P^{2}, P=P^{1}+\lambda P^{2}$, where $\lambda$ is a constant describing how harmful the two pollutants are. ${ }^{9}$ If $\lambda>1, P^{2}$ is more harmful and if $\lambda<1, P^{1}$ has more damaging effects.

Pollutant $P^{1}$ is a flow pollutant. The flow of $P^{1}$ in period $t$ is given by ${ }^{10}$

$$
P_{t}^{1}=g\left(k_{t}, a_{t}^{1}\right)
$$

where $a^{1}$ are the abatement expenditures used to abate the flow pollutant $P^{1} .{ }^{11}$ Higher capital increases pollution and marginal pollution, $g_{k}>0$ and $g_{k k} \geq 0 .{ }^{12}$ Higher abatement expenditures decrease pollution, but by an ever smaller degree because the cheapest abatement opportunities are first exploited, $g_{a}<0$ and $g_{a a}>0$ (for empirical evidence see Faber et al. 1996, p. 272). Contrary to the bulk of the literature which for simplicity assumes $g_{a k}=0,{ }^{13}$ we assume $g_{a k}=g_{k a} \leq 0$ which is more general and plausible: With more capital (more emissions) abatement expenditures are more efficient $\left(g_{a k}\right)$ or with higher abatement expenditures the polluting effect of more capital is smaller $\left(g_{k a}\right) .{ }^{14} \mathrm{~A}$ further assumption is that $\lim _{a^{1} \rightarrow 0}\left|g_{a}\left(\cdot, a^{1}\right)\right|<\infty$. If capital (emissions) is equal to zero, there is no pollution, $g(0, \cdot)=0$. Finally, $P^{1} \geq 0$ must always hold: We assume $\lim _{a^{1} \rightarrow \infty} g\left(\cdot, a^{1}\right)=0$. This is not unreasonable, since the marginal costs of reducing pollution rise steeply as pollution tends towards zero (Neumayer 1998, p. 166).

The second pollutant is a stock pollutant. The stock of $P^{2}$ in period $t$ is given by

$$
P_{t}^{2}=\theta P_{t-1}^{2}+h\left(k_{t-1}, a_{t-1}^{2}\right)
$$

where $a^{2}$ are the abatement expenditures used to abate the stock pollutant $P^{2}$. Nature assimilates a constant share of last period's stock of $P^{2},(1-\theta) P_{t-1}^{2}$ where $0<\theta<1$. But the stock of $P^{2}$ increases because of emissions $h$ where $h_{k}>0$ and $h_{a}<0 .{ }^{15}$ The negative external effect of emissions $h$ are only felt one period later because $P^{2}$ needs time to accumulate and because the 
damage needs time to materialize. ${ }^{16}$ So $P_{t}^{2}$ is given in period $t$ and cannot be altered by actions taken in period $t$. Finally, we assume $h(0, \cdot)=0$.

Following John et al. (1995) we assume a government which collects a per capita $\operatorname{tax} \tau_{t-1}$ on the wage of the young. The government uses the tax revenues to construct abatement technologies for $P^{1}$ and $P^{2}$ which are used in the next period, $\tau_{t-1}=a_{t}^{1}+a_{t}^{2}$. To simplify we assume that at the end of period $t$ the abatement technologies are fully worn out, i.e. the depreciation rate for the abatement technology is $100 \%$. The young lend all their after tax wages, their savings $s_{t-1}=w_{t-1}-\tau_{t-1}$, to the firms. Since consumers give their savings inelastically to the firms, the interest rate $r$ (given in (1)) must adjust to ensure market clearing, $s_{t-1}=k_{t}$. In the next period the firms pay their capital stock, including interest rates, back to the now old who use their savings for consumption, $c_{t}=\left(1+r_{t}\right) s_{t-1}$. The firms receive new capital from the next generation.

In this paper we analyse how the economy develops when in each period a myopic government is in office. In setting the tax rate, $\tau_{t-1}$, and choosing $a_{t}^{1}$ and $a_{t}^{2}$ the myopic government of period $t-1$ maximizes the utility of all people living in period $t-1$. However, the utility of the old is not influenced by this decision as capital and abatement only change in the next period. So the government actually maximizes the utility that the young of period $t-1$ will derive in period $t$ when they are old. Another possibility for setting the wage tax is that there is a vote about how high it should be. Then the old do not vote. Thus it is assumed that all intra-generational externalities are internalized whereas the inter-generational externalities are not. Since $P_{t}^{2}$ is given for generation $t$, this model analyses what can happen when the externality of one pollutant is internalized and the externality of another is not. The government's problem in period $t-1$ is to maximize the utility of the generation which is old in period $t$,

$$
\begin{array}{ll}
\max _{a_{t}^{1}, a_{t}^{2}} & u\left(c_{t}, P_{t}^{1}+\lambda P_{t}^{2}\right) \\
\text { subject to } & \tau_{t-1}=a_{t}^{1}+a_{t}^{2} \\
& s_{t-1}=w_{t-1}-\tau_{t-1} \\
& k_{t}=s_{t-1} \\
& r_{t}=\alpha \beta k_{t}^{\alpha-1}-\delta \\
c_{t}=\left(1+r_{t}\right) s_{t-1} \\
P_{t}^{1}=g\left(k_{t}, a_{t}^{1}\right) \\
a_{t}^{1} \geq 0, a_{t}^{2} \geq 0
\end{array}
$$

taking as given $w_{t-1}$ and $P_{t}^{2}$ since $w_{t-1}$ is determined by $k_{t-1}$ (see (2)) and since $P_{t}^{2}$ cannot be influenced any more (see (3)). Note finally that feasibility requires 


$$
f\left(k_{t}\right)=\delta k_{t}+c_{t}+a_{t+1}^{1}+a_{t+1}^{2}+\left(k_{t+1}-k_{t}\right),
$$

i.e. output $f\left(k_{t}\right)$ is used to finance capital depreciation, $\delta k_{t}$, consumption in this period, $c_{t}$, abatement in the next period, $a_{t+1}^{1}+a_{t+1}^{2}$, and growth of the capital stock, $k_{t+1}-k_{t}$.

\section{Derivation of the Phase Diagram}

We first study the solution in a given period, i.e. the solution the government chooses given $P_{t}^{2}$ and $k_{t-1}$. Then we derive the phase diagram in the $P_{t}^{2}-k_{t-1}$ space.

Since $a_{t}^{2}$ does not show up in the utility function and since it competes with $a_{t}^{1}$ and $k_{t}$ for the use of $w_{t-1}\left(w_{t-1}=a_{t}^{1}+a_{t}^{2}+k_{t}\right)$, it is clear that $a_{t}^{2}=0$ : The myopic government in period $t-1$ never abates the stock pollutant because this has only an effect on $P^{2}$ in period $t+1$ which the myopic government neglects. Instead it abates the flow pollutant which has an immediate effect or it lets capital grow which increases consumption: Inserting (6) and (7) into (8) we can write consumption as a function of the capital stock,

$$
\begin{aligned}
& c_{t}=c\left(k_{t}\right)=(1-\delta) k_{t}+\alpha \beta k_{t}^{\alpha}, \\
& c_{k}=\mathrm{d} c / \mathrm{d} k=1-\delta+\alpha^{2} \beta k_{t}^{\alpha-1}>0, \quad c_{k k}=\alpha^{2}(\alpha-1) \beta k_{t}^{\alpha-2}<0 .
\end{aligned}
$$

Setting $a_{t}^{2}=0$ it follows that maximizing with respect to $a_{t}^{1}$ is equivalent to maximizing with respect to $k_{t}$ because $w_{t-1}=a_{t}^{1}+k_{t}$ where $w_{t-1}$ is given. Inserting (4) - (6), (9) and (11) into the utility function, the problem of the myopic government simplifies to

$$
\max _{k_{t}} u\left[c\left(k_{t}\right), g\left(k_{t}, w_{t-1}-k_{t}\right)+\lambda P_{t}^{2}\right]+\phi\left(w_{t-1}-k_{t}\right)
$$

where $\phi$ is the multiplier of the nonnegativity constraint $a_{t}^{1} \geq 0$. Dividing the first order condition by $-u_{P}$ we find ${ }^{17}$

$$
\operatorname{MRS} \cdot c_{k}=g_{k}-g_{a}-\phi / u_{P} .
$$

Next we analyse how the solution changes either when stock pollution $P_{t}^{2}$ is higher or when last period's capital stock $k_{t-1}$ (and thus last period's wage $w_{t-1}$ ) is higher. For an interior solution (with $a^{1}>0$ and $\phi=0$ ) we find the following Lemma:

Lemma 1. If $P_{t}^{2}$ rises, the capital stock, $k_{t}$, falls, but abatement expenditures, $a_{t}^{1}$, grow in the optimum. If $k_{t-1}$ rises, the optimal level of $k_{t}$ and $a_{t}^{1}$ both increase.

The proof is given in Appendix A. Intuitively, as $P_{t}^{2}$ rises, the marginal damage of pollution rises so that we abate more. Since $a_{t}^{1}+k_{t}$ equals $w_{t-1}$, a 
higher $a_{t}^{1}$ implies a smaller $k_{t}$. Furthermore, if the wage (or $k_{t-1}$ ) rises, capital and abatement increase since consumption and environmental quality (or $-P)$ are both normal goods.

For every given level of $k_{t-1}$ and $P_{t}^{2}$ we can therefore determine the optimal level of $k_{t}$ and $a_{t}^{1}$. Then (3) gives the stock of $P_{t+1}^{2}$. Hence, using a phase diagram in the $P_{t}^{2}-k_{t-1}$ space we can analyse how the economy evolves over time when the government of each period $t-1$ myopically maximizes the utility of period $t$.

Before we derive the phase diagram note that we have so far assumed that abatement expenditures are positive. However, the economy can be so poor and endowed with such a small stock of $P^{2}$ inherited from earlier generations that it is not worth to abate any flow pollution $P^{1}$. Thus we can find a line in the phase diagram - the $a_{t}^{1}=0$-line - below which abatement expenditures are optimally chosen to be zero.

Lemma 2. Abatement expenditures, $a_{t}^{1}$, are zero at low levels of $k_{t-1}$ and of $P_{t}^{2}$, i.e. below the $a_{t}^{1}=0$-line in Figure 1. The $a_{t}^{1}=0$-line is downward sloping.

The proof is provided in Appendix A. Intuitively, with a higher stock of pollution abatement is more attractive and thus starts to increase at a lower level of capital.

To analyse the myopically optimal path in the phase diagram we have to derive the $\bar{k}$-line on which capital stays constant, $k_{t}=k_{t-1}$, and the $\vec{P}^{2}$-line on which the stock of $P^{2}$ stays constant, $P_{t+1}^{2}=P_{t}^{2}$. To characterize the $\bar{k}$-line we need an additional assumption:

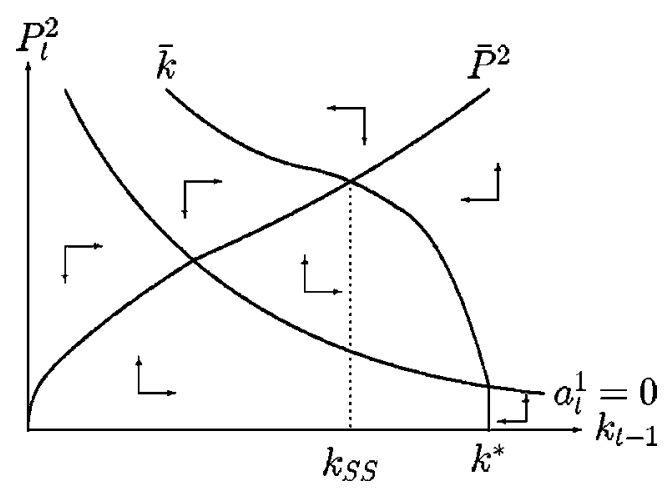

Figure 1. The phase diagram. 
Assumption 1. Along the $\bar{k}$-line $\partial k_{t} / \partial k_{t-1}<1$ is satisfied. In other words,

$$
\begin{aligned}
X:= & \operatorname{MRS}_{c} c_{k}^{2}+\operatorname{MRS}_{k k}+\operatorname{MRS}_{P} c_{k} g_{k}-g_{k k}+g_{a k} \\
& +\left(1-w_{k_{t-1}}\right)\left(g_{a k}-g_{a a}-\operatorname{MRS}_{P} c_{k} g_{a}\right)<0
\end{aligned}
$$

holds, where $w_{k_{t-1}}=\mathrm{d} w_{t-1} / \mathrm{d} k_{t-1}$.

Note that assumption 1 is surely satisfied if $1-w_{k_{t-1}} \geq 0$. This is the case for large $k$. In the proof of Lemma 3 we show that assumption 1 is not restrictive.

Lemma 3. (1) Below the $a_{t}^{1}=0$-line the $\bar{k}$-line is vertical at $k^{*}$ where

$$
k^{*}=[(1-\alpha) \beta]^{\frac{1}{1-\alpha}} .
$$

Above the $a_{t}^{1}=0$-line the $\bar{k}$-line is negatively sloped if assumption 1 holds. To the left (right) of the $\bar{k}$-line capital rises (falls) as indicated by the arrows in Figure 1.

(2) The $\bar{P}^{2}$-line is positively sloped, but becomes flatter when it crosses the $a_{t}^{1}=0$-line from below. To the left (right) of the $\vec{P}^{2}$-line $P^{2}$ falls (rises) as shown in Figure 1.

The proof is relegated to Appendix A. The $\bar{k}$-line is downward sloping because $k_{t}$ rises less than proportionally with $k_{t-1}$ according to assumption 1 . So $P_{t}^{2}$ must fall to ensure that $k_{t}$ increases at the same speed as $k_{t-1}$. The $\vec{P}^{2}$ line is upward sloping because with a higher stock of $P_{t}^{2}$ nature assimilates more $\left((1-\theta) P_{t}^{2}\right)$ and thus emissions generated by capital can be higher. There is exactly one intersection of the $\bar{k}$ - and the $\bar{P}^{2}$-line, i.e. exactly one steady state. The steady state capital stock is $k_{S S}$. We will not analyse the steady state more closely since it will turn out that the steady state is not important for our argument.

\section{The Equilibrium Path of Myopic Governments}

Let us now analyse what the equilibrium path of a succession of myopic governments looks like. To analyse the interesting case in which an EKC might emerge we assume that the steady state lies above the $a_{t}^{1}=0$-line and that we start below the $a_{t}^{1}=0$-line, i.e. we assume that we start with small levels of capital and of the stock pollutant. The optimal path is depicted in the lower panel of Figure 2. Since the main purpose of this model lies in the explanation of the empirical evidence and since empirically capital is always growing, we only analyse the path until the maximal capital stock is reached. Considering this part of the path we can now prove one of the main results of this paper: 


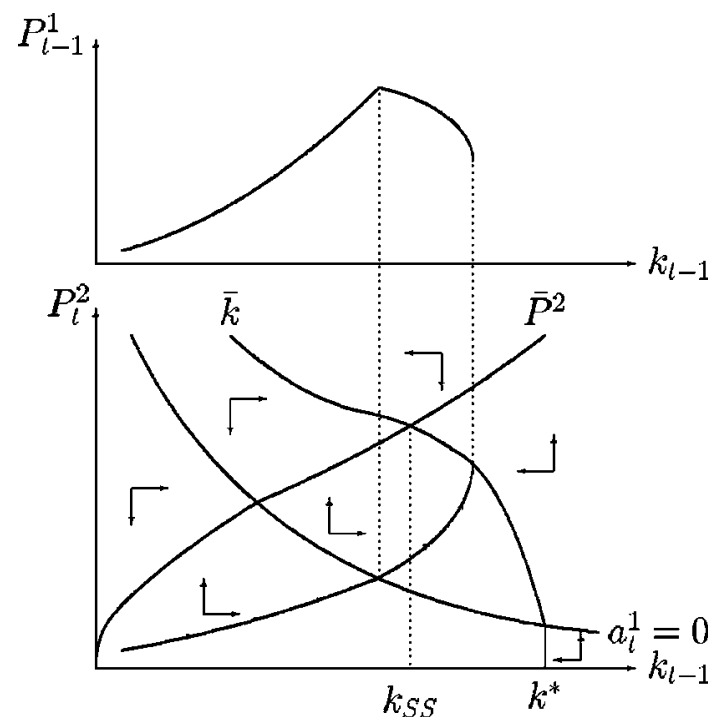

Figure 2. The myopically optimal path of the economy.

Proposition 1. The flow pollutant $P^{1}$ first rises and then falls: There is an EKC for $P^{1}$. The stock pollutant $P^{2}$, however, rises throughout.

Proof. We first show that $P^{2}$ rises. Capital overshoots its steady state stock because the stock pollutant $P^{2}$ needs time to accumulate: Suppose that $P^{2}$ is in an equilibrium in which the assimilated stock, $(1-\theta) P_{t}^{2}$, equals newly generated emissions, $h\left(k_{t}, 0\right)$ (see (3)). If emissions then suddenly increased and stayed at their higher level forever, $P^{2}$ would immediately start to rise, but would only approach its new equilibrium level asymptotically. ${ }^{18}$ Since capital is growing along the optimal path (see Figure 2), emissions "suddenly" increase in every period. So $P^{2}$ does not have the time to accumulate. Therefore $P^{2}$ is still smaller than its steady state stock when the economy reaches its steady state capital stock, $k_{S S} .{ }^{19}$ It follows from the phase diagram that capital continues to grow: Capital overshoots. It reaches its maximal value when it crosses the $\bar{k}$-line. Hence, $P^{2}$ rises along the optimal path until the maximal capital stock is reached. That the PIR of $P^{2}$ is monotonically rising is not surprising since myopic governments never abate stock pollution.

It remains to be discussed how $P^{1}$ changes along the optimal path. As long as abatement expenditures are zero, $P^{1}=g(k, 0)$ increases with capital. For an interior solution we use $P_{t}^{1}=g\left(k_{t}, a_{t}^{1}\right)$ and (18) and (19) from the proof of Lemma 1 to derive 


$$
\begin{aligned}
\Delta P_{t}^{1}= & g_{k} \frac{\partial k_{t}}{\partial k_{t-1}} \Delta k_{t-1}+g_{a} \frac{\partial a_{t}^{1}}{\partial k_{t-1}} \Delta k_{t-1}+g_{k} \frac{\partial k_{t}}{\partial P_{t}^{2}} \Delta P_{t}^{2}+g_{a} \frac{\partial a_{t}^{1}}{\partial P_{t}^{2}} \Delta P_{t}^{2} \\
= & \frac{-w_{k_{t-1}}\left[g_{k}\left(g_{a a}-g_{a k}\right)+g_{a}\left(g_{k k}-g_{a k}\right)-g_{a}\left(\mathrm{MRS}_{c} c_{k}^{2}+\mathrm{MRS}_{k k}\right)\right]}{\operatorname{MRS}_{c} c_{k}^{2}+\mathrm{MRS}_{k k}+\mathrm{MRS}_{P} c_{k}\left(g_{k}-g_{a}\right)-g_{k k}+2 g_{a k}-g_{a a}} \Delta k_{t-1} \\
& +\frac{\left(g_{a}-g_{k}\right) \lambda \mathrm{MRS}_{P} c_{k}}{\operatorname{MRS}_{c} c_{k}^{2}+\mathrm{MRS}_{k k}+\mathrm{MRS}_{P} c_{k}\left(g_{k}-g_{a}\right)-g_{k k}+2 g_{a k}-g_{a a}} \Delta P_{t}^{2}
\end{aligned}
$$

where $\Delta x_{t}=x_{t}-x_{t-1}$ for $x=P^{1}, P^{2}, k$. The fraction in the second line of (14) is negative as expected: If stock pollution increases, the incentive to abate becomes larger and thus flow pollution is more likely to decline. The fraction in the first line of (14) is negative if

$$
g_{k}\left(g_{a a}-g_{a k}\right)+g_{a}\left(g_{k k}-g_{a k}\right)-g_{a}\left(\mathrm{MRS}_{c} c_{k}^{2}+\mathrm{MRS}_{k k}\right)
$$

is negative. This in turn is surely negative, if $g_{k}\left(g_{a a}-g_{a k}\right)+g_{a}\left(g_{k k}-g_{a k}\right) \leq 0$. The pollution function $g\left(k, a^{1}\right)$ fulfils this condition in simple examples, but violates it in more elaborate examples. ${ }^{20}$ Therefore (15) can be positive or negative.

On the one hand, if (15) is negative, $P^{1}$ falls at an interior solution because $\Delta k_{t-1}$ and $\Delta P_{t}^{2}$ are both positive before the path reaches the $k$-line in the lower panel of Figure 2. Hence, below the $a_{t}^{1}=0$-line $P^{1}$ increases along the optimal path, but as soon as abatement expenditures become positive, $P^{1}$ declines as shown in the upper panel of Figure 2. The EKC lies in the $P^{1}-$ GDP space. Since GDP $=f(k)$ increases with capital, the inverted U-shaped path in the $P^{1}-k$ space also implies an EKC for the flow pollutant. ${ }^{21}$

On the other hand, if (15) is positive, $P^{1}$ falls along the path if the path is relatively steep after crossing the $a_{t}^{1}=0$-line, i.e. it follows from (14) that $\Delta P^{1} \leq 0$ if

$$
\frac{\Delta P_{t}^{2}}{\Delta k_{t-1}} \geq \frac{w_{k_{t-1}}\left[g_{k}\left(g_{a a}-g_{a k}\right)+g_{a}\left(g_{k k}-g_{a k}\right)-g_{a}\left(\mathrm{MRS}_{c} c_{k}^{2}+\mathrm{MRS}_{c_{k k}}\right)\right]}{\left(g_{a}-g_{k}\right) \lambda \mathrm{MRS}_{P} c_{k}} .
$$

This condition is surely satisfied before the path reaches the $\bar{k}$-line where the slope of the path becomes infinity. Thus even if the path is relatively flat ((16) violated) directly after crossing the $a_{t}^{1}=0$-line such that $P^{1}$ continues to increase, $P^{1}$ starts to fall before the $\bar{k}$-line is reached. ${ }^{22}$ Hence, we also find an EKC.

The main driving force behind the $\mathrm{EKC}$ for $P^{1}$ is that we first are at a corner solution with zero abatement expenditures, but later on abatement 
increases. The fact that an EKC emerges for $P^{1}$ even if abatement of $P^{1}$ is costly, can be explained by the rise of $P^{2}$ : Since $P^{2}$ always grows and since myopic governments only abate $P^{1}$, additional income is mainly used to abate $P^{1}$. So capital grows slowlier and $P^{1}$ falls. The result of proposition $1-$ an EKC for the flow pollutant but a monotonically rising PIR for the stock pollutant - is consistent with the empirical evidence. Furthermore, from the proof of Proposition 1 we can draw two conclusions which are presented in the next section.

\section{Two Important Consequences}

It is often concluded from the finding of an EKC for a few pollutants that all other pollutants also follow an EKC. ${ }^{23}$ In our model, however, the EKC for $P^{1}$ is accompanied by a monotonically rising PIR for $P^{2}$. Hence, this conclusion is clearly wrong in our model. Even worse, if we assume that there is no stock pollutant or - put differently - that the stock "pollutant" is harmless, i.e. if $\lambda=0$, there might not be an EKC for $P^{1}$ :

Proposition 2. Suppose that (15) is positive along the optimal path, i.e. that a higher $k_{t-1}$ increases $P_{t}^{1}$. Then the PIR for $P^{1}$ is monotonically rising if the stock pollutant is harmless, i.e. if $\lambda=0$.

Proof. If $\lambda=0$, the second line in (14) drops out. ${ }^{24}$ So $P^{1}$ is monotonically increasing if (15) is positive.

If there is another, ever rising pollutant which cannot be abated in the short-run $(\lambda>0)$, an EKC for $P^{1}$ arises as shown in Proposition 1. In contrast, if there is no such pollutant $(\lambda=0)$, the PIR for $P^{1}$ is monotonically rising if (15) is positive. Hence, we might only observe EKCs for certain flow pollutants because the stock of other pollutants is increasing.

If $P^{2}$ is harmless, we are back at a one-pollutant model. In this case the model and in particular the condition for rising or falling pollution at an interior solution (i.e. (15)) is very similar to the model of Lieb (2002). ${ }^{25}$ Hence, without the stock pollutant the PIR for the flow pollutant behaves just as the PIR in the model of Lieb (2002): There is an EKC for $P^{1}$ when there is a sufficiently strong tendency to satiation in consumption (see Lieb 2002 , pp. 438 and 433). With the specific functional forms of the model of Stokey (1998) - a special case of the model of Lieb (2002, pp. 443-444) - the PIR is an EKC, if there is asymptotic satiation in consumption, and the PIR is monotonically rising, if there is no satiation. Thus when there is no satiation in consumption, the PIR of the flow pollutant is monotonically rising without a stock pollutant. But the existence of a stock pollutant causes the PIR of the flow pollutant to become an EKC because of the additional incentive to abate pollution. 
A second important result also follows from the proof of Proposition 1:

Proposition 3. Suppose that flow pollution starts declining as soon as abatement expenditures become positive, i.e. suppose that (15) is negative or that (15) is positive and that (16) holds. Then the turning point of the EKC for $P^{1}$ lies at lower levels of income and of $P^{1}$, if one of the following conditions is satisfied where we always hold all other variables constant: If the (endogenously given) stock of $P^{2}$ is higher, if $P^{2}$ is more harmful (higher $\lambda$ ), if production is more $P^{1}$-intensive $\left(g(k, 0)\right.$ and $g_{k}(k, 0)$ higher), if abatement is cheaper $\left(\left|g_{a}(k, 0)\right|\right.$ higher), if preferences are "greener" (MRS smaller), and if consumption is higher $(c(k)$ higher), but rises slowlier with capital ( $c_{k}$ smaller).

Proof. If $P^{1}$ starts declining as soon as $a^{1}$ becomes positive and if the optimal path crosses the $a_{t}^{1}=0$-line at a low capital stock, the turning point of the EKC occurs at a low capital stock and also at a low level of $P^{1}=g(k, 0)$. If $P^{2}$ is high, i.e. if the initial stock of $P^{2}$ is high and if $P^{2}$ rises fast with capital for $a^{1}=0$ (due to high $\theta$ and high $h(k, 0)$, see (3)), the economy reaches the $a_{t}^{1}=0$-line at a smaller capital stock (see Figure 2).

The optimal path also crosses the $a_{t}^{1}=0$-line at a small capital stock if the $a_{t}^{1}=0$-line lies at small levels of $P^{2}$. The $a_{t}^{1}=0$-line is defined by $\operatorname{MRS}\left(c(k), g(k, 0)+\lambda P^{2}\right) c_{k}=g_{k}(k, 0)-g_{a}(k, 0)$ (see (12)). Hence, for a given capital stock the $a_{t}^{1}=0$-line lies at low levels of $P^{2}$ if $g(k, 0)$ and $\lambda$ are high. Pollution $P$ (and thus $P^{2}$ for given $g(k, 0)$ and $\lambda$ ) is low, if the MRS is high, i.e. if $g_{k}$ and $\left|g_{a}\right|$ are high and if $c_{k}$ is low. If the MRS tends to be small due to high $c(k)$ or due to "green" preferences (MRS small for given $c, P$ ), then $P$ and $P^{2}$ must be small for given $c_{k}, g_{k}$, and $g_{a}$.

Therefore if "background pollution" $\left(P^{2}\right)$ is higher and more harmful, the turning point of the EKC for $P^{1}$ lies at lower levels of capital and of flow pollution. Furthermore, for different pollutants $P^{1}$ or for different pollution functions $g$ in different countries if production is $P^{1}$-intensive or if abatement is cheap, $a^{1}$ turns positive at a lower capital stock. So the model can also accommodate the observation of different turning points for different pollutants $P^{1}$ or in different countries. High consumption or "green" preferences cause the marginal utility of consumption to be small relative to the marginal disutility of pollution. Then the turning point occurs at lower levels of capital and of $P^{1}$.

Most empirical studies assume that the turning point of the EKC occurs at the same income level in all countries. However, this is not an appropriate assumption because recent studies (see Koop and Tole 1999; List and Gallet 1999; de Bruyn 2000, pp. 105-106) allow for and find different turning points in different countries. This empirical finding is theoretically underpinned by Proposition 3 since "background pollution", its harmfulness, ${ }^{26}$ 
the pollution function $g$, and the utility function all tend to be different in different countries. Further support for Proposition 3 is supplied by de Bruyn (1997, p. 496) and List and Gallet (1999, p. 422): They find evidence that the turning point lies at a lower income level if pollution is high, i.e. if $P^{1}$ is high.

\section{Conclusion}

The finding of an EKC for certain pollutants has often been seen as a sign for optimism. Thus "most governments and global institutions see no conflict between economic growth [and environmental degradation]" (Cole 1999, p. 91). However, in this paper we have shown that the downturn of the EKC for a flow pollutant might be due to the neglect of future damages and due to ever rising stock pollution. Therefore we claim that great care must be taken when interpreting the results of EKC studies. In particular, we cannot conclude from the finding of an EKC for some (flow) pollutants that other (stock) pollutants also follow an inverted-U shaped path. Furthermore, falling flow pollution might only be achieved at (high) long-run costs.

In this paper we have given an explanation of the empirical finding that the PIR is an EKC for flow pollutants, but that the PIR is monotonically rising for stock pollutants. We have analysed an overlapping generations model with a flow and a stock pollutant. It has been shown that a succession of myopic governments follows a path on which there is an EKC for the flow pollutant, but on which the stock pollutant is ever rising. This is consistent with the empirical evidence. It is actually due to the monotonically rising stock pollutant that we surely find an EKC for the flow pollutant: Myopic governments want to keep aggregate pollution at a reasonably low level. However, since abating emissions of the stock pollutant does not have an immediate effect on the level of stock pollution, myopic governments abate flow pollution only. Thus stock pollution is rising. Hence, myopic governments increase abatement expenditures for the flow pollutant. This causes the EKC.

If there was no stock pollutant, in contrast, we might observe an ever rising PIR for the flow pollutant. As in the model of Lieb (2002) and Stokey (1998) this is the case if there is no satiation in consumption. We have also found that the turning point of the myopically optimal EKC for the flow pollutant lies at lower levels of income and of flow pollution if stock pollution is high and harmful. Similarly, the turning point lies at a small income level if flow pollution is high. This casts doubts on most empirical EKC studies because they assume that the turning point occurs at the same income level in all countries. However, it is consistent with recent empirical studies which find that the PIR differs between countries. 
If the EKC for flow pollution is actually caused by the neglect of future damages and by ever rising stock pollution, the EKC is bad news for future generations. Indeed, in this case, since all observed EKCs are based on past data, the EKC is bad news for us.

\section{Acknowledgements}

I am indebted to Till Requate and Clive Bell for extremely useful comments on earlier drafts of this paper. Suggestions by Sjak Smulders, Sander de Bruyn, Andreas Lange and two anonymous referees were helpful as well. I also thank the Graduiertenkolleg "Environmental and Resource Economics" which is sponsored by the "Deutsche Forschungsgemeinschaft" for financial support.

\section{Notes}

1. Since all empirical EKC studies consider $\mathrm{SO}_{2}$ and $\mathrm{NO}_{x}$ only as air pollutants, we treat them as such. We therefore neglect that they are also stock pollutants causing acidification of soils, fens, and lakes.

2. If waste is incinerated, about $30 \%$ of its original weight remain for disposal (Nentwig 1995, p. 347).

3. For a more thorough survey of the empirical literature on the EKC see Lieb (2003).

4. We will never be able to determine all adverse effects that synthetic chemicals - pure and in mixture - have on the environment because the costs would be prohibitive and because it is impossible to analyse the effects on all species since we do not even know all species (Huesemann 2001, p. 274).

5. If the government regulates only some pollutants, but leaves other pollutants unregulated, the firms substitute away from the regulated to the unregulated pollutants (Devlin and Grafton 1994).

6. Following John and Pecchenino (1994) we therefore simplify by concentrating on the choice between investment in pollution abatement and investment in physical capital (see below) and by abstracting from the consumption-saving choice.

7. If we assumed $u_{c c}<0, u_{P P}<0$, and $u_{c P} \leq 0$ as is common in the literature and as John and Pecchenino (1994) do, $\mathrm{MRS}_{c}<0$ and $\mathrm{MRS}_{P}<0$ would both hold. However, we do not need these stronger, cardinal assumptions. The above ordinal assumptions are sufficient to derive our results.

8. If we did not assume a Cobb-Douglas production function, we would have to assume $f_{k}>0, f_{k k}<0, f_{k k k}>0, f_{k}+k f_{k k}>0, f_{k k}+k f_{k k k}>0$, and $2 f_{k k}+k f_{k k k}<0$. Therefore we use the simple Cobb-Douglas function which fulfils all these conditions and additionally allows to explicitly derive two further results in (13) and note 28 below.

9. The public is only concerned about aggregate damage, but does not care which pollutant is responsible for this damage. Furthermore, the assumption that (aggregate) pollution is a weighted sum of two pollutants also allows to simplify the model.

10. Here we deviate substantially from John and Pecchenino (1994). First, these authors take environmental quality instead of pollution. The finding of an EKC in their model might 
therefore suggest that the EKC applies to environmental quality generally - an interpretation which is heavily criticized by Arrow et al. (1995). Second, the natural level of environmental quality in the model of John and Pecchenino (1994) is zero. It is unclear what a positive level of environmental quality, i.e. a higher level than the natural one, should be. John and Pecchenino (1994) write that environmental quality might be interpreted as the inverse of the concentration of CFCs. Then a natural level of zero means that the natural concentration of CFCs is infinity, i.e. the worst possible level. In the model of John et al. (1995) the natural level of environmental quality - which is again zero - is also the worst possible level because it is assumed that environmental quality is always positive. In contrast, we assume that pollution is always nonnegative. Third, in our model pollution is generated by capital, whereas in the model of John and Pecchenino (1994) it is generated by consumption. Fourth, John and Pecchenino (1994) assume that environmental quality depends linearly on consumption and abatement, contrary to the literature where it is assumed that $P_{c c}>0$ (or $P_{k k}>0$ ) and $P_{a a}>0$ (Forster 1973; Gruver 1976; Selden and Song 1995; McConnell 1997; Ansuategi et al. 1998; Ansuategi and Perrings 2000; Lieb 2002).

11. Of course, pollution depends on total capital $K_{t}$ and total abatement expenditures $A_{t}^{1}$, but since we do not consider population growth, we can normalize $L=1$ such that $k_{t}=K_{t}$ and $a_{t}^{1}=A_{t}^{1}$.

12. Pollution might also result from output $f(k)$ instead of being caused by capital $k$. If pollution is rising with $k$, it is also rising with $f(k)$ because $f(k)$ is strictly increasing in $k$. Thus the sign of the slope of the PIR is the same for both models. Following the literature (Forster 1973; Gradus and Smulders 1993; Selden and Song 1995; van Ewijk and van Wijnbergen 1995; Smulders and Gradus 1996; Ansuategi and Perrings 2000) we choose pollution to be generated by capital.

13. This assumption can be found in John and Pecchenino (1994), as well as in Forster (1973), Gruver (1976), John et al. (1995), Selden and Song (1995), McConnell (1997), Ansuategi et al. (1998), and Ansuategi and Perrings (2000).

14. Suppose for example that a certain abatement technology can abate a certain percentage of emissions. A higher percentage is achieved by a more expensive technology. Then the higher capital, i.e. the higher emissions, the higher are the emissions which can be abated by a given technology $\left(g_{a k}\right)$. On the other hand, the higher abatement expenditures, the less polluting is higher capital because a higher percentage of the additional emissions is abated $\left(g_{k a}\right)$.

15. Although it is often stated that in the case of $\mathrm{CO}_{2}$ available abatement technologies are prohibitively expensive (see for example Nentwig 1995, p. 231; Vogel 1999, p. 126), these technologies do exist. The costs of depositing $\mathrm{CO}_{2}$ underground or in the deep sea are even reasonably low (Herzog et al. 2000).

16. For $\mathrm{CO}_{2}$ estimates of the time lag between increases in radiative inputs and the climate change range from 6 to 95 years (Nordhaus 1991, p. 922).

17. A graphical interpretation of (12) is available from the author. This graphical interpretation also shows that the second order condition for a maximum is satisfied and allows to prove Lemma 1 graphically.

18. Suppose that emissions rise to $\epsilon:=h(k, 0)$ in period $T$. The new equilibrium value of $P^{2}$ is $\vec{P}^{2}=\epsilon /(1-\theta)$. In period $T$ we know that $P_{T}^{2}=\pi \vec{P}^{2}$ where $\pi<1$. So the difference to the equilibrium is $(1-\pi) \vec{P}^{2}$. According to (3) next periods stock is given by $P_{T+1}^{2}=\theta \pi \epsilon /$ $(1-\theta)+\epsilon=(1-\theta+\theta \pi) \epsilon /(1-\theta)$ and the difference is now $\bar{P}^{2}-P_{T+1}^{2}=\theta(1-\pi) \epsilon /$ $(1-\theta)=\theta(1-\pi) \vec{P}^{2}$. Therefore the difference to the equilibrium declines to a constant fraction $\theta$ of the difference in the last period. 
19. The assumption that the path goes directly into the steady state leads to a contradiction: In the period in which the steady state is reached, capital is growing. Thus $P^{2}$ cannot yet be at its steady state level since it needs time to accumulate.

20. It is straightforward to show that $g_{k}\left(g_{a a}-g_{a k}\right)+g_{a}\left(g_{k k}-g_{a k}\right) \leq 0$ is satisfied for $g\left(k, a^{1}\right)=\tilde{g}(k)-\beta a^{1}$ where $\tilde{g}_{k}>0, \tilde{g}_{k k} \geq 0$, and $\beta>0$. However, it is violated for $g\left(k, a^{1}\right)=k^{\eta}\left(k+a^{1}\right)^{1-\eta}$ where $\eta>1$ and for $g\left(k, a^{1}\right)=\beta k^{\alpha} /\left(\gamma a^{1}+1\right)^{\delta}$ where $\alpha \geq 1$ and $\beta$, $\gamma, \delta>0$.

21. This holds also true if we use income $=f(k)-\delta k$ instead of GDP $(d$ (income $) / d k=$ $f_{k}-\delta=r>0$, see (1) and note 28 below).

22. This is a continuous time argument which might be wrong in our discrete time model. However, since the model is aimed at explaining the empirical evidence, we do not give any weight to this theoretical possibility.

23. See for example Beckerman (1992, pp. 482 and 491), Li (1989, p. 147), and Kelly (2003, p. 1368).

24. In addition, the $a_{t}^{1}=0$ - and the $\bar{k}$-line are both vertical (see (20) and (21) in the proofs of Lemma 2 and 3.1). Thus capital does no longer overshoot its steady state stock.

25. Dividing (15) by $-g_{a}$ we see that (15) becomes very similar to Equation (10) in Lieb (2002).

26. If $P^{2}$ is a global pollutant such as $\mathrm{CO}_{2}$, "background pollution" is equal in all countries. However, not all countries are equally affected by global warming ( $\lambda$ differs across countries).

27. The same conclusion would also follow if we assumed that $\lim _{c \rightarrow 0} \operatorname{MRS}=\infty$.

28. There is yet another reason why capital cannot grow infinitely. If the interest rate $r_{t}$ fell below zero, consumers would not give all their savings to the firms, but would only supply capital until $r_{t}=0$. So $k \leq \check{k}$ holds always where $\check{k}$ is defined by $r(\check{k})=\alpha \beta \check{k}^{\alpha-1}-\delta=0$ (see (1)) or $\check{k}=(\alpha \beta / \delta)^{1 /(1-\alpha)}$. It follows from (13) that $\check{k}>k^{*}$ if $\alpha / \delta>1-\alpha$. We assume that $\delta$ is sufficiently small to fulfil this condition so that we do not have to bother about $\check{k}$.

\section{References}

Agras, J. and D. Chapman (1999), 'A Dynamic Approach to the Environmental Kuznets Curve hypoThesis'. Ecological Economics 28, 267-277.

Ansuategi, A., E. Barbier and C. Perrings (1998), 'The Environmental Kuznets Curve', in J. C. J. M. van den Berg and M. W. Hofkes, eds., Economic Modelling of Sustainable Development: Between Theory and Practice, (pp. 139-164). Dordrecht: Kluwer Academic Publishers.

Ansuategi, A. and C. Perrings (2000), 'Transboundary Externalities in the Environmental Transition Hypothesis', Environmental and Resource Economics 17 (4), 353-373.

Arrow, K., B. Brolin, R. Costanza, P. Dasgupta, C. Folke, C.S. Holling, B.-O. Jansson, S. Levin, K.-G. Mäler, C. Perrings and D. Pimentel (1995), 'Economic Growth, Carrying Capacity, and the Environment', Ecological Economics 15, 91-95. (Reprinted from Science 268, 520-521.)

Barrett, S. and K. Graddy (2000), 'Freedom, Growth, and the Environment', Environment and Development Economics 5, 433-456.

Beckerman, W. (1992), 'Economic Growth and the Environment: Whose Growth? Whose Environment?', World Development 20(4), 481-496.

Carson, R. T., Y. Jeon and D. R. McCubbin (1997), 'The Relationship between Air Pollution Emissions and Income: US Data', Environment and Development Economics 2 , 433-450. 
Cavlovic, T. A., K. H. Baker, R. P. Berrens and K. Gawande (2000), 'A Meta-Analysis of Environmental Kuznets Curve Studies', Agricultural and Resource Economics Review 29(1), 32-42.

Cole, M. A. (1999), 'Limits to Growth, Sustainable Development and Environmental Kuznets Curves: An Examination of the Environmental Impact of Economic Development', Sustainable Development 7, 87-97.

Cole, M. A. (2000), Trade Liberalisation, Economic Growth and the Environment. Cheltenham, UK: Edward Elgar.

Cole, M. A., A. J. Rayner, and J. M. Bates (1997), 'The Environmental Kuznets Curve: An Empirical Analysis', Environment and Development Economics 2, 401-416.

de Bruyn, S. M. (1997), 'Explaining the Environmental Kuznets Curve: Structural Change and International Agreements in Reducing Sulphur Emissions', Environment and Development Economics 2, 485-503.

de Bruyn, S. M. (2000), Economic Growth and the Environment: An Empirical Analysis. Economy and Environment Volume 18, Dordrecht, The Netherlands: Kluwer Academic Publishers.

Devlin, R. A. and R. Q. Grafton (1994), 'Tradeable Permits, Missing Markets, and Technology', Environmental and Resource Economics 4, 171-186.

Dinda S., D. Coondoo and M. Pal (2000), 'Air Quality and Economic Growth: An Empirical Study', Ecological Economics 34, 409-423.

Faber, M., F. Jöst, R. Manstetten, G. Müller-Fürstenberger and J.L.R. Proops (1996), 'Linking Ecology and Economy: Joint Production in the Chemical Industry', in M. Faber, R. Manstetten, and J. L. R. Proops, eds., Ecological Economics - Concepts and Methods, (Chapter 13, pp. 263-278). Cheltenham, UK: Edward Elgar.

Forster, B. A. (1973), 'Optimal Capital Accumulation in a Polluted Environment', Southern Economic Journal 39, 544-547.

Frey, R. L., E. Staehelin-Witt and H. Blöchliger (1991), Mit Ökonomie zur Ökologie: Analyse and Lösungen des Umweltproblems aus ökonomischer Sicht. Basel, Switzerland: Helbling \& Lichtenhahn.

Friedl, B. and M. Getzner (2003), 'Determinants of $\mathrm{CO}_{2}$ Emissions in a Small Open Economy', Ecological Economics 45, 133-148.

Gradus, R. and S. Smulders (1993), 'The Trade-off Between Environmental Care and Longterm Growth - Pollution in Three Prototype Models', Journal of Economics 58(1), 25-51.

Grossman, G. M. (1995), 'Pollution and Growth: What do We Know?', in I. Goldin and L. A. Winters, eds., The economics of sustainable development. New York: Cambridge University Press, pp.19-46.

Grossman, G. M. and A. B. Krueger (1993), 'Environmental Impacts of a North American Free Trade Agreement', in Peter M. Garber, ed., The Mexico-U.S. Free Trade Agreement (pp. 13-57). Cambridge, Massachusetts: The MIT Press,

Grossman, G. M. and A.B. Krueger (1995), 'Economic Growth and the Environment', Quarterly Journal of Economics 110, 353-377.

Gruver, G. W. (1976), 'Optimal Investment in Pollution Control Capital in a Neoclassical Growth Context', Journal of Environmental Economics and Management 3, 165-177.

Halkos, G. E. and E. G. Tsionas (2001), 'Environmental Kuznets Curves: Baysian Evidence from Switching Regime Models', Energy Economics 23, 191-210.

Heil, M. T. and T. M. Selden (2001), 'Carbon Emissions and Economic Development: Future Trajectories based on Historical Experience', Environment and Development Economics 6, 63-83.

Herzog, H., B. Eliasson and O. Kaarstad (2000), 'Die Entsorgung von Treibhausgasen', Spektrum der Wissenschaft May 2000, 48-56. 
Hettige, H., M. Mani and D. Wheeler (2000), 'Industrial Pollution in Economic Development: The Environmental Kuznets Curve Revisited', Journal of Development Economics 62, 445-476.

Hill, R. J. and E. Magnani (2002), 'An Exploration of the Conceptual and Empirical Basis of the Environmental Kuznets Curve', Australian Economic Papers 41(2), 239-254.

Holtz-Eakin, D. and T. M. Selden (1995), 'Stocking the Fires? $\mathrm{CO}_{2}$ Emissions and Economic Growth', Journal of Public Economics 57, 85-101.

Huesemann, M. H. (2001), 'Can Pollution Problems be Effectively solved by Environmental Science and technology? An Analysis of Critical Limitations', Ecological Economics 37, 271-287.

IPCC (Intergovernmental Panel on Climate Change) (1996), 'Climate Change 1995: The Science of Climate Change'. Cambridge: Cambridge University Press.

John, A. and R. Pecchenino (1994), 'An Overlapping Generations Model of Growth and the Environment', Economic Journal 104, 1393-1410.

John, A., R. Pecchenino, D. Schimmelpfennig and S. Schreft (1995), 'Short-lived Agents and the Long-lived Environment', Journal of Public Economics 58, 127-141.

Kaufmann, R. K., B. Davisdottir, S. Garnham and P. Pauly (1998), 'The Determinants of Atmospheric $\mathrm{SO}_{2}$ Concentrations: Reconsidering the Environmental Kuznets Curve', Ecological Economics 25, 209-220.

Kelly, D. L. (2003), 'On Environmental Kuznets Curves Arising from Stock Externalities', Journal of Economic Dynamics and Control 27(8), 1367-1390.

Koop, G. and L. Tole (1999), 'Is there an Environmental Kuznets Curve for Deforestation?', Journal of Development Economics 58, 231-244.

Li, E. A. L. (1989), 'An Environmental Cooperation Agreement for the Asia-Pacific Region?', The Australian Economic Review 32(2), 145-156.

Lieb, C.M. (2002), 'The Environmental Kuznets Curve and Satiation: A Simple Static Model', Environment and Development Economics 7, 429-448.

Lieb, C.M. (2003), 'The Environmental Kuznets Curve: A Survey of the Empirical Evidence and of Possible Causes'. University of Heidelberg, Department of Economics, Discussion Paper No. 391. Available at http://www.uni-heidelberg.de/institute/fak18/awi/index_d. html

Lim, J. (1997), 'The Effects of Economic Growth on Environmental Quality: Some Empirical Investigation for the Case of South Korea', Seoul Journal of Economics 10(3), 273-292.

List, J. A. and C. A. Gallet (1999), 'The Environmental Kuznets Curve: Does One Size Fit All?', Ecological Economics 31, 409-423.

List, J.A. and S. Gerking (2000), 'Regulatory Federalism and Environmental Protection in the United States', Journal of Regional Science 40(3), 453-471.

Liu, D. H. F. and B. G. Lipták (2000), Air Pollution. Boca Raton, Florida: Lewis publishers.

McConnell, K. E. (1997), 'Income and the Demand for Environmental Quality', Environment and Development Economics 2, 383-399.

Millimet, D. L., J. A. List and T. Stengos (2003), 'The Environmental Kuznets Curve: Real Progress or Misspecified Models?', Review of Economics and Statistics 85, 1038-1047.

Minliang, Z., C. A. Withagen and H. L. F. de Groot (2001), 'Dynamics of China's Regional Development and Pollution: An Investigation into the Existence of an Environmental Kuznets Curve', Paper presented at the EAERE Conference, Southampton, UK, June 2001. Available at http://www.soton.ac.uk/ eaere/conf2001/conf2001.html.

Moomaw, W. R. and G. C. Unruh (1997), 'Are Environmental Kuznets Curves Misleading Us? The Case of $\mathrm{CO}_{2}$ Emissions', Environment and Development Economics 2, 451-463.

Nentwig, W. (1995), Humanökologie: Fakten - Argumente - Ausblicke. Berlin: Springer-Verlag. Neumayer, E. (1998), 'Is Economic Growth the Environment's Best Friend?', Zeitschrift für Umweltpolitik und Umweltrecht 21(2), 161-176. 
Nordhaus, W. D. (1991), 'To Slow or not to Slow: The Economics of the Greenhouse Effect', The Economic Journal 101, 920-937.

Panayotou, T. (1995), 'Environmental Degradation at Different Stages of Economic Development', in I. Ahmed and J.A. Doeleman, eds., Beyond Rio: The Environmental Crisis and Sustainable Livelihoods in the Third World (pp. 13-36). ILO Study Series, New York: St. Martin's Press.

Panayotou, T. (1997), 'Demystifying the Environmental Kuznets Curve: Turning a Black Box into a Policy Tool', Environment and Development Economics 2, 465-484.

Perrings, C. and A. Ansuategi (2000), 'Sustainability, Growth and Development', Journal of Economic Studies 27(1/2), 19-54.

Roberts, J. T. and P. E. Grimes (1997), 'Carbon Intensity and Economic Development 19621991: A Brief Exploration of the Environmental Kuznets Curve', World Development 25(2), 191-198.

Roca, J., E. Padilla, M. Farré and V. Galletto (2001), 'Economic Growth and Atmospheric Pollution in Spain: Discussing the Environmental Kuznets Curve Hypothesis', Ecological Economics 39, 85-99.

Saint-Paul, G. (1995), 'Discussion of 'Pollution and Growth: What do We Know?', in I. Goldin and L. A. Winters, eds., The Economics of Sustainable Development (pp. 47-50). New York: Cambridge University Press.

Schmalensee, R., T. M. Stoker and R. A. Judson (1998), 'World Carbon Dioxide Emissions: 1950-2050'. Review of Economics and Statistics 80, 15-27.

Scruggs, L. A. (1998), 'Political and Economic Inequality and the Environment', Ecological Economics 26, 259-275.

Selden, T. M. and D. Song (1994), 'Environmental Quality and Development: Is There a Kuznets Curve for Air Pollution Emissions', Journal of Environmental Economics and Management 27, 147-162.

Selden, T. M. and D. Song (1995), 'Neoclassical Growth, the J Curve for Abatement, and the inverted U Curve for Pollution', Journal of Environmental Economics and Management 29, $162-168$.

Shafik, N. (1994), 'Economic Development and Environmental Quality: An Econometric Analysis', Oxford Economic Papers 46, 757-773.

Smulders, S. (2000), 'Economic Growth and Environmental Quality', in H. Folmer and H.L. Gabel, eds., Principles of Environmental and Resource Economics (pp. 602-664), 2nd edn. Cheltenham: Edward Elgar.

Smulders, S. and R. Gradus (1996), 'Pollution Abatement and Long-term Growth', European Journal of Political Economy 12, 505-532.

Stern, D. I. and M. S. Common (2001), 'Is There an Environmental Kuznets Curve for Sulfur?', Journal of Environmental Economics and Management 41, 162-178.

Stokey, N. L. (1998), ‘Are There Limits to Growth?'. International Economic Review 39, 1-31.

Torras, M. and J. K. Boyce (1998), 'Income, Inequality, and Pollution: A Reassessment of the Environmental Kuznets Curve'. Ecological Economics 25, 147-160.

van Ewijk, C. and S. van Wijnbergen (1995), 'Can Abatement Overcome the Conflict Between Environment and Economic Growth?'. De Economist 143(2), 197-216.

van Kooten, G. C. and E. H. Bulte (2000), 'The Ecological Footprint: Useful Science or Politics?', Ecological Economics 32, 385-389.

Vogel, M. P. (1999), Environmental Kuznets Curves: A Study on the Economic Theory and Political Economy of Environmental Quality Improvements in the Course of Economic Growth. Lecture Notes in Economics and Mathematical Systems 469. Berlin: SpringerVerlag. 
Wu, P. I. (1998), 'Economic Development and Environmental Quality: Evidence from Taiwan', Asian Economic Journal 12 (4), 395-412.

\section{Appendix A: Proofs}

\section{Proof of Lemma 1}

Totally differentiating (12) at an interior solution (where $\phi=0$ ) yields

$$
\begin{aligned}
\left(\operatorname{MRS}_{c} c_{k}^{2}+\right. & \left.\operatorname{MRS}_{k k}+\operatorname{MRS}_{P} c_{k}\left(g_{k}-g_{a}\right)\right) \mathrm{d} k_{t}+\operatorname{MRS}_{P} c_{k} g_{a} w_{k_{t-1}} \mathrm{~d} k_{t-1} \\
& +\lambda \mathrm{MRS}_{P} c_{k} \mathrm{~d} P_{t}^{2} \\
= & \left(g_{k k}-2 g_{a k}+g_{a a}\right) \mathrm{d} k_{t}+\left(g_{k a}-g_{a a}\right) w_{k_{t-1}} \mathrm{~d} k_{t-1}
\end{aligned}
$$

where it follows from (2) that $w_{k_{t-1}}=\mathrm{d} w_{t-1} / \mathrm{d} k_{t-1}=\alpha(1-\alpha) \beta k_{t-1}^{\alpha-1}>0$. Holding $P_{t}^{2}$ or $k_{t-1}$ constant, respectively, we find

$$
\begin{aligned}
\frac{\partial k_{t}}{\partial k_{t-1}} & =\frac{w_{k_{t-1}}\left(g_{a k}-g_{a a}-\operatorname{MRS}_{P} c_{k} g_{a}\right)}{\operatorname{MRS}_{c} c_{k}^{2}+\operatorname{MRS}_{k k}+\operatorname{MRS}_{P} c_{k}\left(g_{k}-g_{a}\right)-g_{k k}+2 g_{a k}-g_{a a}}>0 \\
\frac{\partial k_{t}}{\partial P_{t}^{2}}= & \frac{-\lambda \mathrm{MRS}_{P} c_{k}}{\operatorname{MRS}_{c} c_{k}^{2}+\operatorname{MRS}_{k k}+\operatorname{MRS}_{P} c_{k}\left(g_{k}-g_{a}\right)-g_{k k}+2 g_{a k}-g_{a a}}<0 .
\end{aligned}
$$

To see how $a_{t}^{1}$ changes with $k_{t-1}$ and $P_{t}^{2}$ we totally differentiate $a_{t}^{1}=w_{t-1}-k_{t}$ to obtain

$$
\mathrm{d} a_{t}^{1}=w_{k_{t-1}} \mathrm{~d} k_{t-1}-\frac{\partial k_{t}}{\partial k_{t-1}} \mathrm{~d} k_{t-1}-\frac{\partial k_{t}}{\partial P_{t}^{2}} \mathrm{~d} P_{t}^{2}
$$

So using (18) we derive

$$
\begin{aligned}
\frac{\partial a_{t}^{1}}{\partial P_{t}^{2}}=-\frac{\partial k_{t}}{\partial P_{t}^{2}} & =\frac{\lambda \mathrm{MRS}_{P} c_{k}}{\operatorname{MRS}_{c} c_{k}^{2}+\operatorname{MRS}_{k k}+\operatorname{MRS}_{P} c_{k}\left(g_{k}-g_{a}\right)-g_{k k}+2 g_{a k}-g_{a a}}>0 \\
\frac{\partial a_{t}^{1}}{\partial k_{t-1}} & =\frac{w_{k_{t-1}}\left(\mathrm{MRS}_{c} c_{k}^{2}+\operatorname{MRS}_{k k}+\operatorname{MRS}_{P} c_{k} g_{k}-g_{k k}+g_{a k}\right)}{\operatorname{MRS}_{c} c_{k}^{2}+\operatorname{MRS}_{k k}+\operatorname{MRS}_{P} c_{k}\left(g_{k}-g_{a}\right)-g_{k k}+2 g_{a k}-g_{a a}}>0
\end{aligned}
$$

Note that $\partial a_{t}^{1} / \partial k_{t-1}+\partial k_{t} / \partial k_{t-1}=w_{k_{t-1}}$.

\section{Proof of Lemma 2}

If capital goes to zero, the left hand side of (12) goes to infinity as $\lim _{k \rightarrow 0} c_{k}=\infty$ (see (11)). ${ }^{27}$ However, $g_{k}-g_{a}$ on the right hand side of (12) is bounded since $\lim _{a^{1} \rightarrow 0}\left|g_{a}\right|<\infty$. Therefore for small capital stocks $\phi>0$ and $a^{1}=0$ must hold.

The $a_{t}^{1}=0$-line is defined by (12) with $a_{t}^{1}=0=\phi$. Totally differentiating (12) yields (17). Inserting $\mathrm{d} k_{t}=w_{k_{t-1}} \mathrm{~d} k_{t-1}$ which holds for $a_{t}^{1}=0$ (see (4) - (6)) we find

$$
\left.\frac{\mathrm{d} P_{t}^{2}}{\mathrm{~d} k_{t-1}}\right|_{a_{t}^{1}=0}=\frac{w_{k_{t-1}}\left(\mathrm{MRS}_{c} c_{k}^{2}+\operatorname{MRS}_{k k}+\mathrm{MRS}_{P} c_{k} g_{k}-g_{k k}+g_{a k}\right)}{-\lambda \mathrm{MRS}_{P} c_{k}}<0 .
$$

Therefore the $a_{t}^{1}=0$-line is downward sloping. Since $\partial a_{t}^{1} / \partial P_{t}^{2}>0$ (see (19)), $a^{1}$ would be negative below the $a_{t}^{1}=0$-line. Because this is not feasible, abatement expenditures are zero below the $a_{t}^{1}=0$-line. 


\section{Proof of Lemma 3}

1. As long as abatement is zero, the government is actually doing nothing at all. The path of capital is derived from (6), (5), and (2) to be

$$
k_{t}=s_{t-1}=w_{t-1}=(1-\alpha) \beta k_{t-1}^{\alpha} .
$$

This is shown in Figure 3 (the curvature of the $w_{t-1}$-line is derived from (2)). Suppose that $k_{t-1}=x k^{*}$ where $x>0$ and where $k^{*}$ is given in (13). It follows that

$$
k_{t}=(1-\alpha) \beta\left(x k^{*}\right)^{\alpha}=x^{\alpha}[(1-\alpha) \beta]^{\frac{1}{1-\alpha}}=x^{\alpha} k^{*}=x^{\alpha-1} k_{t-1} .
$$

Capital stays only constant, i.e. $k_{t}=k_{t-1}$, if $x=1$, i.e. $k_{t-1}=k^{*}$. The $\bar{k}$-line is vertical at $k^{*}$ and thus independent of $P_{t}^{2}$ as shown in Figure 1 . As $\alpha-1<0$, it also follows that if $x<1$, i.e. if $k_{t-1}<k^{*}$, capital is growing (see arrows in Figure 1), but $k_{t}=x^{\alpha} k^{*}$ is still smaller than $k^{*}$ (see Figure 3). If $x>1$, capital is decreasing. Thus $k^{*}$ is a stable steady state which is only approached asymptotically. ${ }^{28}$

Turning to the interior solution $\left(a^{1}>0\right)$ we totally differentiate $k_{t}=k_{t-1}$ which holds on the $\bar{k}$-line to find $\frac{\partial k_{t}}{\partial k_{t-1}} \mathrm{~d} k_{t-1}+\frac{\partial k_{t}}{\partial P_{t}^{2}} \mathrm{~d} P_{t}^{2}=\mathrm{d} k_{t-1}$. Inserting (18) and $X$ from assumption 1 we derive

$$
\begin{aligned}
& \left.\frac{\mathrm{d} P_{t}^{2}}{\mathrm{~d} k_{t-1}}\right|_{k_{t}=k_{t-1}}=\frac{1-\partial k_{t} / \partial k_{t-1}}{\partial k_{t} / \partial P_{t}^{2}}=\frac{X}{-\lambda \mathrm{MRS}_{P} c_{k}} \\
& =\frac{\operatorname{MRS}_{c} c_{k}^{2}+\mathrm{MRS}_{k k}+\mathrm{MRS}_{P} c_{k} g_{k}-g_{k k}+g_{a k}+\left(1-w_{k_{t-1}}\right)\left(g_{a k}-g_{a a}-\mathrm{MRS}_{P} c_{k} g_{a}\right)}{-\lambda \mathrm{MRS}_{P} c_{k}}<0
\end{aligned}
$$

where the sign follows from assumption 1. As mentioned $X<0$ is surely satisfied if $1-w_{k_{t-1}} \geq 0$ or $1 \geq \alpha(1-\alpha) \beta k_{t-1}^{\alpha-1}$ holds. Therefore we derive that $X$ is negative for $k_{t-1} \geq \tilde{k}:=[\alpha(1-\alpha) \beta]^{1 /(1-\alpha)}$. This is almost identical with $k^{*}=[(1-\alpha) \beta]^{1 /(1-\alpha)}$ except for the additional factor $\alpha$ (see (13)). So $\tilde{k}$ is smaller than $k^{*}$ (see Figure 3). Therefore for $k_{t-1} \geq \tilde{k}$ assumption 1 is a fact, not an assumption. Note that it follows immediately from (20) and (21) that the $\bar{k}$-line is more negatively sloped than the $a_{t}^{1}=0$-line at $k^{*}\left(\left.\left(\mathrm{~d} P_{t}^{2} / \mathrm{d} k_{t-1}\right)\right|_{a_{t}^{1}=0}>\right.$ $\left.\left(\mathrm{d} P_{t}^{2} / \mathrm{d} k_{t-1}\right)\right|_{k_{t}=k_{t-1}}$ since $1-w_{k_{t-1}}>0$ at $\left.k^{*}\right)$. Hence, starting from $k^{*}$ the interior $\bar{k}$-line moves north-west (see Figure 1). At some capital stocks smaller than $\tilde{k}$, however, $X$ might become zero

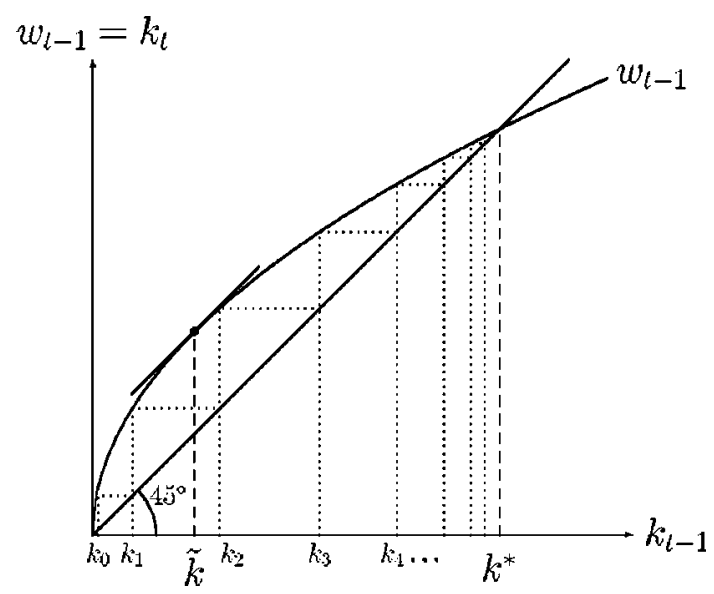

Figure 3. Growth of capital without abatement. 
and positive causing the $\bar{k}$-line to move west and south-west. But the $\bar{k}$-line crosses the $a_{t}^{1}=0$ line only once - at $k^{*}$ to be precise. Thus for $k<k^{*}$ the $\bar{k}$-line lies always above the $a_{t}^{1}=0$-line. Consequently, the $\bar{k}$-line cannot move south-west for very long, but must move north-west again. We simplify by assuming that the $\bar{k}$-line is always moving north-west, i.e. $X<0$ (Assumption 1). Below the $\bar{k}$-line $P_{t}^{2}$ is smaller. So according to (18) $k_{t}$ is higher: Capital is growing as indicated by the arrows in Figure 1. Similarly, above the $\bar{k}$-line capital is falling. 2. On the $\vec{P}^{2}$-line pollution assimilated by nature is equal to newly generated emissions

$$
(1-\theta) P_{t}^{2}=h\left(k_{t}, 0\right)
$$

(see (3)). For $a_{t}^{1}=0$ this becomes $(1-\theta) P_{t}^{2}=h\left(w_{t-1}, 0\right)$. So we find

$$
\left.\frac{\mathrm{d} P_{t}^{2}}{\mathrm{~d} k_{t-1}}\right|_{P_{t+1}^{2}=P_{t}^{2} \text { and } a_{t}^{1}=0}=\frac{h_{k} w_{k_{t-1}}}{1-\theta}>0 .
$$

Thus the $\bar{P}^{2}$-line is rising below the $a_{t}^{1}=0$-line as shown in Figure 1 . Note that the $\bar{P}^{2}$-line begins at the origin where it is vertical since $\lim _{k_{t-1} \rightarrow 0} w_{k_{t-1}}=\infty$.

Finally, we consider $a_{t}^{1}>0$. Totally differentiating (22) and rearranging we derive

$$
\left.\frac{\mathrm{d} P_{t}^{2}}{\mathrm{~d} k_{t-1}}\right|_{P_{t+1}^{2}=P_{t}^{2}}=\frac{h_{k} \partial k_{t} / \partial k_{t-1}}{(1-\theta)-h_{k} \partial k_{t} / \partial P_{t}^{2}}>0
$$

where the sign follows from (18). So the $\vec{P}^{2}$-line is also rising above the $a_{t}^{1}=0$-line. The $\vec{P}^{2}$-line becomes flatter when it crosses the $a_{t}^{1}=0$-line from below: Compared to (23) the denominator of (24) is higher and the numerator is smaller (since $\partial k_{t} / \partial k_{t-1}<\partial k_{t} / \partial k_{t-1}+\partial a_{t}^{1} / \partial k_{t-1}=$ $w_{k_{t-1}}$ ). To the left of the $\vec{P}^{2}$-line $k_{t-1}$ is smaller and therefore $k_{t}$ is smaller such that assimilation is higher than new emissions $(1-\theta) P_{t}^{2}>h\left(k_{t}, 0\right)$. Thus $P^{2}$ is falling (see Figure 1). To the right of the $\vec{P}^{2}$-line $P^{2}$ is rising. 